\title{
Kronik obstrüktif akciğer hastalığında orbital kan akım değişikliklerinin renkli doppler ultrasonografi ile değerlendirilmesi
}

\author{
Orbital blood flow changes with color doppler ultrasound evaluation in chronic \\ obstructive pulmonary disease
}

\author{
Gülay Çetin*, Mübeccel Arslan, İsmail Şalk, Abdi Bahadır Çetin \\ Radyoloji Kliniği (Dr. G. Çetin), Göz Hastalıkları Kliniği (Dr. A. B. Çetin), Sivas Numune \\ Hastanesi, TR-58100 Sivas, Radyoloji Anabilim Dalı (Prof. Dr. M. Arslan, Yrd. Doç. Dr. İ. Şalk), \\ Cumhuriyet Üniversitesi Tıp Fakültesi, TR-58140 Sivas
}

\begin{abstract}
Özet
Amaç. Kronik obstrüktif akciğer hastalığı (KOAH) olgularının oküler kan akım hızlarını ölçüp oküler hemodinaminin etkilenip etkilenmediğini saptamaktır. Yöntem. 2009-2010 yılları arasında Global Initiative for Chronic Obstructive Lung Disease (GOLD) kriterlerine göre değerlendirilerek 20 'er kişilik 4 gruba ayrılan KOAH tanılı 80 hasta ve rastgele seçilen 63 sağliklı birey olmak üzere toplam 143 olgunun Renkli doppler ultrasonografi (RDUS) tekniği ile santral retinal arter (SRA) ve oftalmik arter (OA) pik sistolik hızları (PSH), end diastolik hızları (EDH), rezistif indeksleri (RI) ve santral retinal ven (SRV) akım hızları ölçüldü. Bulgular. SRA ve OA PSH ve Rİ değerlerinde gruplarda anlamlı yükseklikler saptanırken $(p<0,05)$ EDH değerlerinde istatistiksel olarak anlamlı yükseklik saptanmadı $(\mathrm{p}>0,05)$. SRV akım hızlarında anlamlı bir biçimde yükseklik saptand $1(\mathrm{p}<0,05)$. Sonuç. SRA ve OA'ya ait olan PSH ve Rİ parametrelerindeki değişikliklere; KOAH'ta meydana gelen hipoksi sonucu oluşan sistemik enflamasyonun ve lokal metabolitlerin retinanın otoregülasyon mekanizmasını bozarak sebep olduğunu düşünmekteyiz. SRV akım hızındaki artışı, oküler kan akımındaki artışa bağlı olarak oftalmik vene dönen akım miktarının artmasına ve KOAH'ta mevcut olan yüksek santral venöz basınca bağlamaktayız.
\end{abstract}

Anahtar sözcükler: Renkli Doppler ultrasonografi, oküler kan akımı, kronik obstrüktif akciğer hastalığ1

\begin{abstract}
Aim. The aim of this study is to investigate ocular hemodynamic affects of COPD, measuring ocular blood flow with Chronic Obstructive Pulmonary Disease (COPD). Method. Between 2009 and 2010 years, total of 80 patients with COPD staged by the Global Initiative for Chronic Obstructive Lung Disease (GOLD) criteria into four groups were enrolled in our study. Each group included 20 patients. Total of 63 healthy people selected randomly were accepted as control group. Peak systolic velocity (PSV), end diastolic velocity (EDV) and resistive index (RI) were calculated in the central retinal artery (CRA) and the ophthalmic artery (OA) respectively. The flow velocity of central retinal vein (CRV) was also measured. All of measurements were obtained for patients and control groups. Results. PSV and RI values of CRA and OA were significantly higher in the patient groups $(p<0.05)$. But there was no statistically significance in EDV values $(p>0.05)$. Furthermore significant increase of CRV measurements was detected $(p<0.05)$. Conclusion. We thought that the changes of PSV and RI parameter in CRA and OA depend on hypoxia with COPD causes systemic and local inflammatory metabolites due to distortion of retinal auto regulatory mechanism. The elevation increase CRV is attributed to amount of blood return to the ophthalmic vein by means of ocular blood flow increase, and to the increased central venous blood pressure related to COPD.
\end{abstract}

Keywords: Color Doppler ultrasonography, ocular blood flow, chronic obstructive pulmonary disease

Geliş tarihi/Received: 12 Ağustos 2014; Kabul tarihi/Accepted: 20 Eylül 2014

*Iletişim adresi:

Dr. Gülay Çetin, Radyoloji Kliniği, Sivas Numune Hastanesi, TR-58040 Sivas. E-posta: gulaykerman@gmail.com 


\section{Giriş}

Geri dönüşümü tam olmayan, zararlı gaz ve partiküllere özelliklede sigara dumanına karşı oluşan enflamatuar bir süreç sonucu gelişen ilerleyici hava akımı kısıtlanması ile karakterize bir hastalık olan kronik obstrüktif akciğer hastalığı (KOAH) ülkemizin önemli bir halk sağlığ 1 sorunudur [1, 2]. Renkli doppler ultrasonografi (RDUS); hemodinamik değişikliklerin değerlendirilmesinde noninvaziv olması, kısa sürmesi, herhangi bir ilaç gerektirmeyip hastayı rahatsız etmemesi, güvenilir ve sonuçlarının tekrarlanabilir olması açısından önemli bir tetkiktir [3, 4]. RDUS ile glokom, arteryel ve venöz oklüziv göz hastalıkları, karotiko-kavernöz fistül, hipertansif ve diyabetik göz patolojileri, oküler ve orbital tümörler, Behçet vasküliti, temporal arterit, karotit arter stenozu ve oküler iskemik sendromda anormal oküler bulguların tespit edildiği çok sayıda çalışma bulunmaktadır [5-7]. Biz de çalışmamızda KOAH olgularında oküler hemodinaminin etkilenip etkilenmediğini saptamayı amaçladık.

\section{Gereç ve yöntem}

Çalışmamız Cumhuriyet Üniversitesi Tıp Fakültesi Yerel Etik Kurulu'nca onaylandı. Göğüs Hastalıkları Anabilim Dalı'nda solunum fonksiyon testleri (SFT) çalışılıp GOLD kriterlerine göre değerlendirilerek 20'er kişilik 4 gruba ayrılan KOAH tanılı 80 hasta ve 63 sağlıklı birey olmak üzere toplam 143 olgu çalışma kapsamına alındı. Çalışmaya alınan tüm olgular altta yatan herhangi başka bir sistemik hastalık olup olmama riskine karşın, teker teker kan basıncı ölçümüne, kan kimyası profiline, nörolojik ve oftalmik muayeneye tabii tutuldular. Brakiyal arterden yapılan kan basıncı ölçümü tüm değerlendiriciler için Doppler uygulamasından hemen önce yapıldı. Oküler kan akımını ve vasküler direnci etkileyebilecek; polisitemi, temporal arterit, diyabet, sistemik vasküler hastalıkları olanlar, oral olarak kalsiyum kanal blokörleri gibi antihipertansif ilaç kullananlar ve intra oküler basınç (IOB) $>21 \mathrm{mmHg}$ olanlar çalışmaya dahil edilmedi. Ayrıca RDUS'de yanıltıcı olabilecek lens ya da vitröz opasite gösterenler de çalışmaya alınmadı. Tüm olguların her iki gözünün SRA, SRV ve OA'ları renkli Doppler Ultrasonografi cihazı (General Electric LOGIQ 9, USA) ile ve lineer transdüser kullanılarak incelendi. Bu inceleme sirasında SRA ve OA'nın PSH, EDH, Rİ değerleri ve SRV'nin akım hızı ölçüldü.

\section{Bulgular}

KOAH grubundaki 80 olgunun 52'si (\%65) erkek, 28'i (\%35) kadın; kontrol grubundaki 63 olgunun 33'ü $(\% 52,4)$ erkek, 30’u $(\% 47,6)$ kadın idi. KOAH grubundaki olguların yaşlarının ortalaması $61,22 \pm 8,73$; kontrol grubundaki olguların yaşlarının ortalaması $59,82 \pm 9,87$ idi. SRA ve OA-PSH ortalamaları yönünden kontrol ve hasta grubu karşılaştırıldığında Evre 1, 2 ve $3 \mathrm{KOAH}$ grubunda SRA, evre 1, 2, 3 ve $4 \mathrm{KOAH}$ gruplarında OA-PSH ortalamaları anlamlı şekilde yüksekti $(p<0,05)$. SRA PSH'1 Kontrol ve evre 4 grubu arasindaki fark istatistiksel olarak anlamsiz bulundu ( $>00,05)$. SRA ve OA-EDH ortalamaları yönünden kontrol ve KOAH grubu karşılaştırıldığında KOAH gruplarında yükseklik olmasına karşın gruplar arasındaki fark istatistiksel olarak anlamsız bulundu $(p>0,05)$. SRA ve OA-Rİ ortalamaları yönünden kontrol ve KOAH grubu karşılaştırıldığında KOAH grubu Rİ ortalamaları anlamlı şekilde yüksek olduğu görüldü $(\mathrm{p}<0,05)$ (Tablo1, 2) SRV ortalama hızları yönünden kontrol ve KOAH grubu karşılaştırıldığında SRV ortalama hızları tüm gruplarda anlamlı şekilde yüksek bulundu $(\mathrm{p}<0,05)($ Tablo 3). 
Tablo 1. KOAH ve kontrol grubundaki tüm olguların sağ ve sol göz Doppler indeksleri.

\begin{tabular}{lllllll}
\hline & Evre 1 & Evre 2 & Evre 3 & Evre 4 & Kontrol & Sonuç \\
\cline { 2 - 6 } & $\bar{x} \pm \mathrm{S}$ & $\bar{x} \pm \mathrm{S}$ & $\bar{x} \pm \mathrm{S}$ & $\bar{x} \pm \mathrm{S}$ & $\bar{x} \pm \mathrm{S}$ & \\
\hline R-SRA-PSH & $12,85 \pm 2,77$ & $12,95 \pm 3,74$ & $13,45 \pm 5,25$ & $11,25 \pm 4,68$ & $7,75 \pm 5,99$ & F: 8,$58 ; \mathbf{P :} 0,001$ \\
R-SRA-EDH & $2,90 \pm 1,11$ & $3,40 \pm 2,34$ & $3,60 \pm 2,23$ & $3,85 \pm 2,32$ & $3,27 \pm 2,86$ & F: 0,$43 ; \mathbf{P : ~} 0,781$ \\
R-SRA-RI & $0,77 \pm 0,07$ & $0,73 \pm 0,11$ & $0,72 \pm 0,11$ & $0,66 \pm 0,09$ & $0,59 \pm 0,13$ & F: 13,$28 ; \mathbf{P : ~} 0,001$ \\
L-SRA-PSH & $14,70 \pm 6,16$ & $12,65 \pm 4,64$ & $12,55 \pm 3,61$ & $11,05 \pm 3,37$ & $8,11 \pm 6,61$ & F: 7,$10 ; \mathbf{P :} 0,001$ \\
L-SRA-EDH & $2,75 \pm 0,85$ & $3,00 \pm 1,77$ & $3,30 \pm 1,26$ & $3,60 \pm 2,23$ & $3,03 \pm 2,87$ & F: 0,$19 ; \mathbf{P : ~} 0,944$ \\
L-SRA-RI & $0,78 \pm 0,08$ & $0,73 \pm 0,07$ & $0,73 \pm 0,08$ & $0,71 \pm 0,09$ & $0,63 \pm 0,12$ & F: 11,$03 ; \mathbf{P : ~} 0,001$ \\
\hline
\end{tabular}

R-SRA-PSH: Sağ santral retinal arter pik sistolik hızı, R-SRA-EDH: Sağ santral retinal arter enddiastolik hızı, R-SRA-RI: Sağ santral retinal arter rezistif indeksi; L-SRA-PSH: Sol santral retinal arter pik sistolik hızı, L-SRA-EDH: Sol santral retinal arter enddiastolik hızı, L-SRA-RI: Sol santral retinal arter rezistif indeksi.

Tablo 2. KOAH ve kontrol grubundaki olgularda sağ ve sol göz Doppler indeksleri.

\begin{tabular}{|c|c|c|c|c|c|c|}
\hline & Evre 1 & Evre 2 & Evre 3 & Evre 4 & Kontrol & \multirow[t]{2}{*}{ Sonuç } \\
\hline & $\bar{x} \pm \mathrm{S}$ & $\bar{x} \pm \mathrm{S}$ & $\bar{x} \pm \mathrm{S}$ & $\bar{x} \pm \mathrm{S}$ & $\bar{x} \pm \mathrm{S}$ & \\
\hline R-OA-PSH & $28,00 \pm 9,34$ & $33,90 \pm 18,73$ & $31,15 \pm 12,81$ & $36,80 \pm 12,38$ & $18,48 \pm 16,09$ & F: 8,$87 ; \mathbf{P}: 0,001$ \\
\hline R-OA-EDH & $7,45 \pm 3,10$ & $8,80 \pm 5,67$ & $7,50 \pm 4,01$ & $7,50 \pm 4,01$ & $5,66 \pm 5,28$ & $\mathbf{F}: 2,80 ; \mathbf{P}: 0,057$ \\
\hline R-OA-RI & $0,73 \pm 0,08$ & $0,74 \pm 0,06$ & $0,75 \pm 0,08$ & $0,76 \pm 0,06$ & $0,68 \pm 0,13$ & $\mathbf{F}: 3,69 ; \mathbf{P}: 0,007$ \\
\hline L-OA-PSH & $29,90 \pm 15,72$ & $28,05 \pm 15,33$ & $29,65 \pm 8,86$ & $33,65 \pm 11,85$ & $17,0 \pm 14,01$ & $\mathbf{F}: 8,95 ; \mathbf{P}: 0,001$ \\
\hline L-OA-EDH & $8,40 \pm 4,35$ & $6,60 \pm 3,03$ & $7,05 \pm 3,18$ & $9,95 \pm 4,04$ & $5,51 \pm 5,15$ & $\mathbf{F}: 2,54 ; \mathbf{P}: 0,052$ \\
\hline L-OA-RI & $0,71 \pm 0,09$ & $0,74 \pm 0,11$ & $0,75 \pm 0,12$ & $0,70 \pm 0,09$ & $0,66 \pm 0,10$ & $\mathbf{F}: 3,50 ; \mathbf{P}: 0,009$ \\
\hline 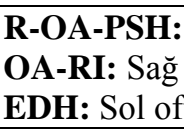 & 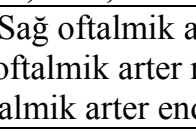 & & & & & diastolik hızı, R- \\
\hline
\end{tabular}

Tablo 3. Sağ ve sol göz SRV akım hızları.

\begin{tabular}{lllllll}
\hline & Evre1 & Evre2 & Evre3 & Evre4 & Kontrol & Sonuç \\
\cline { 2 - 6 } & $\bar{x}_{ \pm \mathrm{S}}$ & $\bar{x}_{ \pm \mathrm{S}}$ & $\bar{x}_{ \pm \mathrm{S}}$ & $\bar{x}_{ \pm \mathrm{S}}$ & $\bar{x}_{ \pm \mathrm{S}}$ & \\
\hline R-SRV & $8,15 \pm 4,63$ & $7,05 \pm 1,73$ & $6,85 \pm 3,55$ & $5,50 \pm 1,96$ & $3,39 \pm 2,56$ & F: 14,$55 ;$ P: 0,001 \\
L-SRV & $7,35 \pm 2,23$ & $6,85 \pm 1,98$ & $6,20 \pm 1,39$ & $4,35 \pm 1,75$ & $3,42 \pm 2,54$ & F: 19,$21 ; \mathbf{P}: 0,001$ \\
\hline
\end{tabular}

\section{Tartışma}

KOAH'da periferal hava yolu obstrüksiyonu, parankimal destrüksiyon ve pulmoner vasküler anormallikler önce sistemik hipoksiye ve ardından hiperkapniye neden olarak akciğerlerin gaz değişim kapasitesini azaltır [8, 9]. Meydana gelen kronik hipoksi ve hiperkapninin oküler arterler üzerindeki etkilerini ele alan çalışmalara da literatürde rastlamaktayız [10, 11]. Akciğerler ve hava yollarındaki enflamasyonun yanısıra, mekanizması kesin olmamakla birlikte sistemik bir enflamasyon geliştiği de gösterilmiştir. Kalp ve damarlar gibi değişik ekstrapulmoner organlar üzerinde de sistemik enflamasyonun etkileri vardır.KOAH'ta akciğer damarlarındaki değișiklikler, damar duvar kalınlaşması ile karakterizedir. Endotelyal disfonksiyon, intimal kalınlaşma, mediyal hipertrofi ve adventisyal enflamasyon meydana gelmektedir. Periferik damarlarda da pulmoner damarlardakine benzer biçimde aterom plakları, trombotik lezyonlar, intima, media ve adventisyada değişiklikler meydana gelmektedir [12-20].

Çalışmamızda SRA'nın ve OA'nın PSH'ları hasta grubunda yüksekti. Özer ve ark. [10] 45 KOAH'lı olgu ile yaptıkları çalışmada Evre 1 KOAH'lı grupta SRA ve OA PSH'ında anlamlı değişiklik saptamazken OA'de Evre 2 ve 3 KOAH gruplarında çalışmamızla benzer olarak anlamlı yüksek bulmuşlardır. Evre 4 KOAH'lı hastaları değişken ve çok kaynaklı olabileceği ve çalışmanın gidişatını değiştireceği düşünülerek çalışma kapsamına almamışlardır. Çalışmamızda Evre 4 hasta grubunda istatistiksel anlamlı fark bulunmamasını bu sebebe bağlayabiliriz. Aynı zamanda Evre 4 hastaların uyum 
problemlerinin bulunması ve sırtüstü yatar pozisyonda toleranslarının daha az olması nedeniyle ölçüm hatalarının olabileceği olası nedenler arasındadır. Çelik ve ark. KOAH'lı 60 olgu ile yaptıkları benzer bir çalışmada ileri evre KOAH grubunda oküler hemodinamide belirgin değişiklikler bulmuşlardır [11].

Akut hipoksi pulmoner vazokonstrüksiyona neden olurken, kronik hipoksi vasküler yatakta yeniden yapılanmaya yol açar. $\mathrm{Bu}$ vasküler yeniden yapılanma retinayı hipoksiden kurtarmak için meydana gelmiş bir savunma mekanizması olabilir [21, 22]. KOAH'lı olgularımızdaki vazospazmı azaltma mekanizması, artmış parsiyel $\mathrm{CO}_{2}$ düzeyinin vazodilatör etkisiyle açıklanabilir. Relatif oksijen açı̆̆ının metabolik talebi karşılamak için kan akım hızını artırarak kompansatuvar sistemi provoke ettiği akla oldukça yatkındır. KOAH'lı olgularımızdaki artmış PSH değerlerinin nedeni muhtemelen bu düzenleyici mekanizmadır. Öte yandan, hipoksemiye sekonder gelişen hiperkapni sonucu bölgesel kan damarlarında vazodilatasyon ve bunun sunucu kan akımı hizında artışına neden olabileceği gösterilmiştir [23-28]. Albayrak ve ark. [29] 29 KOAH'lı hasta ile yaptıkları çalışmada KOAH grubunda bilateral internal serebral arter ve vertebral arter PSH'larında ve total beyin kan akım volümünde anlamlı ölçüde artış tespit etmişler ve bu artışa KOAH'ta meydana gelen sistemik vazokonstrüksiyonun neden olduğunu düşünmüşlerdir. Beyin ve böbrek gibi kan akımının otoregülasyon mekanizmasıyla dengelendiği organlara ilaveten retina ve optik sinir başı kan akımı da otoregülasyon mekanizmasıly dengede tutulmaya çalışılmaktadır. Otoregülasyon mekanizması belirli sınırlar içerisindeki perfüzyon basıncı değişikliklerinde kan akımını sabit tutmayı amaçlar. Yani otoregülasyon mekanizması perfüzyon basıncındaki değişikliklere karşı sağlıklı bir damarın normal bir cevabıdır. Otoregülasyon artan yaş ve sistemik hastalıklarda bozulur [30].

Çalışmamızda SRA ve OA EDH değerlerinde hasta grubunda kontrol grubuna göre yüksek olduğunu bulduk. Özer ve ark. [10] 45 KOAH'lı olgu ile yaptıkları çalışmada SRA ve OA EDH değerlerinde çalışma ve kontrol grupları arasında çalışmamızla benzer şekilde anlamlı bir farklılık saptamamışlardır. EDH, damar çapındaki \%50'den az stenoz durumlarında diastol süresince basınç gradyanı olmaması nedeniyle genellikle normal kalır. Bu nedenle RDUS incelemede EDH nadir kullanılan bir parametre olup özellikle çok ileri düzeydeki darlıklarda iyi bir belirleyicidir [31].

Çalışmamızda SRA ve OA Rİ değerlerini her iki gözde KOAH grubunda kontrol grubuna göre anlamlı olarak yüksek olduğunu gözlemledik. Özer ve ark. [10] 45 KOAH'lı olgu ile yaptıkları çalışmada SRA ve OA'in Rİ değerlerinde Evre 2 ve Evre 3 gruplarında çalışmamızla benzer şekilde anlamlı artış saptamışlar ve bunun sistemik vasospazm sonucu oküler damarlardaki direnç artışına bağlamışlardır. KOAH'da fibrinojen düzeyinde artma, fibrin yıkımında azalma, epitelyal hasar ve trombosit aktivasyonunda artma şeklinde sistemik enflamatuvar reaksiyonu indükleyen bir mekanizma sonucu oluşan vasküler endotelyal hasar, ET-1 salınımı için önemli bir stimulustur ve sıklıkla akciğer hastalıklarıyla seyreden pulmoner yataktaki artmış vazokonstrüksiyona katkıda bulunur. Literatüre bakıldığında; KOAH hastalarında plazma ve idrarda artmış ET-1 konsantrasyonları gösterilmiştir. Plazma seviyesindeki bu ET-1 artışı KOAH'lı hastalarda oküler arter rezistansını artırarak vazospazma yol açtığı bilinmektedir [16, 32]. Çalışmamızdaki SRA ve OA Rİ değerlerindeki artışı sistemik vasospazm sonucu oküler arterlerin rezistansının artmasına bağlamaktayız.

Çalışmamızda her iki gözde SRV hızlarının hasta grubunda kontrol grubuna göre artış gösterdiğini bulduk. Bunu oküler kan akımının artışına sekonder venöz dönüşün artmasına bağladık [28, 29]. Aynı zamanda SRV akım hızındaki artışın KOAH'taki yüksek santral venöz basıncın sonucu olabileceğini düşünmekteyiz [33]. 
Sonuç olarak; KOAH'da meydana gelen kronik hipoksi, sistemik enflamasyon ve lokal mediatörlerin etkisiyle pulmoner damarlarda gelişen vasküler endotelyal hasarın benzerinin oküler damarlarda da meydana gelebileceğini düşünmekteyiz [10, 28]. Çalışmamızda elde ettiğimiz SRA ve OA parametrelerindeki değişiklikler tüm KOAH evrelerinde izlenmekte ve oküler otoregülasyon mekanizmasının bozulduğu düşüncesini kuvvetlendirmektedir. Bundan dolayı KOAH'lı hastalarda oküler RDUS incelemenin daha geniş popülasyonlarla yapılacak çalışmalar ile desteklenerek daha fazla bilgi edinilebileceği düşünülmektedir.

\section{Kaynaklar}

1. Jeffrey PK. Remodelling in asthma and chronic obstructive lung disease. Am J Respir Crit Care Med 2001; 164: 28-38.

2. Fabri LM, Romagnoli M, Corbetta L, Casoni G, Busljetic K, Turato G. Differences in airway inflamation in patients with fixed airflow obstruction due to asthma or chronic obstructive lung disease.Am J Respir Crit Care Med 2003; 167: 418-24.

3. A Mohammadi, N Khorasani, F Moulodi. Evaluation of retrobulbar blood flow in patients with age-related cataract; color Doppler ultrasonographic findings. Ultrasonography.clin Ophthalmol 2011; 5: 1521-4.

4. Giovagnorio F, Quaranta L, Bucci MG. Color Doppler assessment of normal ocular blood flow. J Ultrasound Med 1993; 12: 473-7.

5. Gencer G, Güven D, Zıraman I, Hasıripi H, Koparal S. Hipertansif Retinopatide Retrobulber Hemodinamik Değişikliklerin Renkli Doppler Ultrasonografi İle Değerlendirilmesi. Türkiye klinikleri J Ophthalmol 2002; 11: 201-6.

6. MacKinnon JR, McKillop G, O'Brien C, Swa K, Butt Z, Nelson P. Colour Doppler imaging of the ocular circulation in diabetic retinopathy. Acta Ophthalmol Scand 2000; 78: 386-9.

7. Sönmez M, Erşanlı D, Pekkafalı Z.Behçet hastalığının göz tutulumunun erken saptanmasında orbital arterlerdeki hemodinamik değişikliklerin değeri. Ret-Vit 2006; 14: 175-80.

8. Pauwels RA, Buist AS, Calverley PM, Jenkins CR, Hurd SS. GOLD Scientific Committee global strategy for the diagnosis, management, and prevention of chronic obstructive pulmonary disease NHLBI/WHO Global Initiative for Chronic Obstructive Lung Disease (GOLD) Workshop summary. Am J respir Crit Care Med 2001; 163: 1256-76.

9. Global Initiative For Chronic Obstructive Lung Disease (GOLD). Global strategy for the diagnosis, management and prevention of chronic obstructive lung disease Updated 2008; 4: 24-30.

10. Ozer T, Altin R, Ugurbas SH, Ozer Y, Mahmutyazicioglu K, Kart L. Color Doppler evaluation of the ocular arterial flow changes in chronic obstructive pulmonary disease. Eur J Radiol 2006; 57: 63-8.

11. Celik C, Tokgöz O, Şerifoğlu L. Color Doppler Evaluation of the Retrobulbar Hemodynamic Changes in Chronic Obstructive Pulmonary Disease: COPD and Retrobulbar Hemodynamic Changes.Ultrason Imaging 2014; 36: 177-86.

12. Burgel PR, Nadel JA. Roles of epidermal growth factor receptor activation in epithelial cell repair and mucin production in airway epithelium. Thorax 2004; 59: 992-6.

13. Umut S. KOAH'ta sistemik etkiler. In: Umut S, Yıldırım N, eds. Kronik Obstrüktif Akciğer Hastalığı (KOAH). 1. baskı. Turgut yayıncılık İstanbul 2005: 288-91.

14. Wouters EF, Creutzberg EC, Schols AM. Systemiceffects in COPD. Chest 2002; 121: 127-30.

15. Labiris NR, Ball L, Ramjaun A. Local and systemic effects of frequent pulmonary exacerbations in COPD.Am J Respir Crit care 2012; 5860.

16. Roland M, Bhowmik A, Sapsford RJ, Seemungal TAR, Jeffries DJ, Warner TD. 
Sputum and plasma endothelin-1 levels in exacerbations of chronic obstruktive pulmonary disease. Thorax 2001; 56: 30-5.

17. Kratzer A, Chu HW, Salys J. Endothelial cell adhesion molecule CD 146: implications for its role in the pathogenesis of COPD.The Journal of Pathology 2013; 230: 388-98.

18. Minoguchi K, Yokoe T, Tazaki T. Increased Carotid intima-media thickness and serum inflammatory markers in obstructive sleep apnea. American Journal of Respiratory and Critical Care Medicine 2005; 172: 625-30.

19. Kwon YS, Chi SY, Shin HJ, Kim EY, Yoon BK, Ban HJ. Plasma C-reactive protein and endothelin-1 level in patients with chronic obstructive pulmonary disease and pulmonary hypertension.J Korean Med Sci 2010; 25: 1487-91.

20. Cazzola M, Matera MG, Rogliani P, Page C.Treating systemic effects of COPD. Trends in pharmacological sciences 2007; 28: 544-50.

21. Carp H, Janoff A. Possible mechanism in smokers: In vitro supression of serum elastase inhibitory capacity by fresh cigarette smoke and its prevention by antioxidants. Am Rev Respir Dis 1978; 118: 617-21.

22. Gan Wq, Man SFP, Senthilselvan A, Sin DD. Association between chronic obstructive pulmonary disease and systemic inflammation: A systematic rewiew and meta-analysis. Thorax 2004; 59: 574-80.

23. Eickhoff P, Valipour A, Kiss D, Schreder M, Cekici L, Geyer K. Determinants of systemic vascular function in patients with stable chronic obstructive pulmonary disease. Am J Respir Crit Care Med 2008; 178: 1211-8.

24. Barnes PJ, Celli BE. Systemic manifestations and comorbidities of COPD. Eur Respir J 2009; 33: 1165-85.

25. Shortt AJ, Howell K, O’Brien C, McLoughlin P. Chronic systemic hypoxia causes intra-retinal angiogenesis. J Anat 2004; 205: 349-56.

26. Johnston AJ, Steiner LA, Gupta AK, Menon DK. Cerebral oxygen vasoreactivity and cerebral tissue oxygen reactivity. Br J Anaesth 2003; 90: 774-86.

27. Patterson Jr JL, Heyman A, Battey LL, Ferguson RW. Threshold of response of the cerebral vessels of man to increase in blood carbondioxide. J Clin İnvest 1955; 34: 1857-64.

28. Kergoat H, Faucher C. Effects of oxigen and carbogen breathing on choroidal hemodynamics in humans. Invest Ophthalmol Vis Sci 1999; 40: 2906-76.

29. Albayrak R, Fidan F, Unlu M, Sezer M, Degirmenci B, Acar M, Haftanir A, Yaman M. Extracranial carotid Doppler ultrasound evaluation of cerebral blood flow volume in COPD patients. Respir Med 2006; 100: 1826-33.

30. Anderson DR. Introductory comments on blood flow autoregulation in the optic nerve head and vascular risk factors in glaucoma. Surv Ophthalmol 1999; 43: 59.

31. Bluth El, Wetzner SM, Stavros AT. Carotid duplex sonography: A multiserver recommendation for standardized imaging and Doppler criteria. Radiographics 1988; 8: 487-506.

32. Sofia M, Mormile M, Faraone S, Carrutu P, Alifano M, Di Benedetto G. Increased 24-h endothelin-1 urinary excretion in patients with chronic obstruktive pulmonary disease. Respiration 1994; 61: 263-8.

33. Doepp F, Bahr D, John M, Hoernig S, Valdueza JM, Schreiber SJ. Internal jugular vein valve incompetence in COPD and primary pulmonary hypertension. J Clin Ultrasound 2008; 36: 480-4. 